\title{
Media Credibility Perception Among Millennials in Slovakia
}

\author{
Lucia Vilčeková \\ Faculty of Management, Comenius University in Bratislava, Slovakia \\ lucia.vilcekova@fm.uniba.sk
}

Received: 13 September 2016 / Revised: 19 October 2016 / Accepted: 25 October 2016 /

/ Published online: 20 December 2016

\begin{abstract}
Communication professionals have been facing various challenges and one of them is how to win the audience. Past studies suggest that credibility could be the key. Therefore, credibility can be suggested as one of the key factors driving the traffic of individuals to certain media. By gaining a better understanding of how Millennials perceive credibility, companies can more appropriately plan and execute successful media campaigns directed to this very important public. A survey with 190 respondents - Millennials - was conducted to determine how they perceive the credibility of various media types. To measure the perception of media credibility, 12 characteristics like objectiveness, activity, intelligence, professionalism, etc. were examined. The results of the study revealed general moderate credibility of newspapers and television. The most credible medium for the Millennials is the Internet, especially because of its activity, ability to act fast, independence and objectivity. On the other hand, this cohort sees both television and newspapers as better presented than the Internet. The worst rated feature of television and newspapers was their passivity and political background. When examining statistically significant difference in overall perception, based on the results from the Wilcoxon signed-rank test, we can conclude that the difference in perception of television, newspapers and the Internet was unlikely to occur by chance and the Millennials perceive the Internet as significantly more credible than television and newspapers.
\end{abstract}

JEL classification: M310; M390

Keywords: media, credibility, Millennials

\section{INTRODUCTION}

The media credibility construct is a complex and multidimensional concept. Source, receiver and message - they all interact in the assessment of credibility of media. It is clear that information providers should pay attention to aspects of the source of information if they want to ensure that users see their information as credible and therefore useful. Hence, the perception of credibility varies according to age. Young consumers are a particularly interesting group to consider with regard to credibility. The generation born around 1980 is different from any before in its relationship to information technology, and also in its relationship to information sources. 
Millennials are identified as those born from 1980 or 1981 to the year 2000 and they are seen as a generation with significant purchasing power and influence. Therefore, they are the target group of our research.

\section{LITERATURE REVIEW}

Nowadays, people have a vast choice of information sources. But in many cases, certain information appears to be "better," or "more trustworthy" than other information. The challenge that most people then face is to judge which information is more credible (Hilligos and Soo Yung, 2008). O'Keefe (1990) defined credibility as "judgments made by a perceiver (e.g., a message recipient) concerning the believability of a communicator". Wathen and Burkell (2002) define credibility as 'believability'. In general, credible information sources may be described as trustworthy and therefore credibility is closely related to a general concept of trust. Communication researchers measure the media trust by exploring the source credibility and the message credibility.

\section{Media credibility}

Media credibility research traditionally follows either the medium or the source approach. Medium credibility research focuses on the medium through which a message is delivered as a key predictor of audience evaluation. The source credibility approach focuses on the actual source of the message (Golan and Baker, 2012). Gunther (1992) identified an alternative approach to the study of media credibility, shifting away from the properties of the source and focusing on the properties of the audience. Eveland and Shah (2003) added that research of individual level predictors of media credibility is now emerging as a prominent subfield within media credibility.

Perceptions of the reliability and trustworthiness may be significantly affected by the selection of information sources. In particular, the significance of these criteria is emphasized when information seekers encounter conflicting information. In these situations, they have to assess the credibility and cognitive authority of alternative sources (Savolainen, 2013).

The concept of credibility is not new and has been studied in the ancient Greece - how the speakers persuade audience members. However, studies of the credibility of mass media began interesting in times when the rising number of people started turning to the radio for news instead of newspapers. Another change was brought by television and in the last decade of the 20th century, rise of the Internet led to recent credibility studies comparing traditional sources with this emerging medium (Davood et al., 2010). In sum, since the late 1990s, when the Internet began providing new information interaction environments that allowed users to seek for information and communicate with others in ways never before possible, the concept of credibility has received considerable attention (Hilligoss and Soo Yung, 2008).

The Internet is an environment full of uncertainty and various types of players (Smolková and Smolka, 2016), and an online user always experiences some level of risk. Thus, trust has become the strategy for dealing with uncertain outcomes or future and it is considered one of the most reliable predictors for online behaviors (Gefen, 2000).

The assessment of credibility in the online environment is often much complex than in previous media contexts due to "the multiplicity of sources embedded in the numerous layers of online dissemination of content" (Sundar, 2008). Stavrositu and Sundar (2008) concluded that using one platform (e.g. newspapers) can actually affect how people perceive the credibility of a different medium (e.g. the Internet). They also determined that news credibility perceptions are based on the reason why an individual is using the one specific platform. 


\section{Millennials}

Generational cohort theory is based on idea that populations can be grouped into generations based upon placement in the historical cycle because specific historic events shape the attitudes and behaviors of members within each cohort. Though this theory comes from the USA, global homogenization supported by technology drives the development of cross border cohorts (Schewe and Meredith, 2004). Generational cohort theory is commonly applied to market analysis because of its ability to target the market efficiently and effectively. The cohort analysis methodological approach has been present in the literature for over thirty years and continues to be strategically relevant in today's data intensive market environment.

Young consumers are a particularly interesting group to consider with regard to credibility (Olšavský, 2013). The generation born around 1980 is different from any before in its relationship to information technology, and also in its relationship to information sources. Known variously as "The Millennials," the "Net Generation," "Digital Natives," members of this generation share the feature of having been born to an environment of digital technologies (e.g., computers and the Internet) and they have been using them for their entire lives. Their experience with digital media has led them to have new and different expectations about how to gather, work with, translate, and share information (Flanagin and Metzger, 2008).

The Millennial generation has grown up with technology and considers social media and the Internet an integral part of their lives. This, along with their sheer number and buying power, makes them an ideal public for companies and their marketing activities (McCorkindale, DiStaso and Sisco, 2013).

\section{Millennials and media credibility}

It has been found that the Millennials differ from other generations in terms of their media usage. Gangadharbatla, Bright and Logan (2014) confirmed the popular notions in trade press that young adults are increasingly turning to social media for news rather than using traditional media such as print newspapers, magazines, and radio. Interestingly, however, despite their preference for using social media for newsgathering, young adults still perceive traditional media as more credible news sources than social media. This apparent disconnect between perceived credibility and actual choice of a medium for news is indicative of the complex nature of newsgathering. A study among Turkish and New Zealand respondents indicated that the Millennials rate print media as important information sources (Ashill and Yavas, 2005). In Taiwan, compared with the Internet, print media, along with television, are less reliable sources (Calisir, 2003). According to Berndt (2007), the Millennials find television more credible than print media. Tsang et al. (2004) confirm the attitudes of Millennials towards traditional media (especially television and magazine advertisements) are negative in comparison with attitudes towards new media, such as cell phones and the Internet.

Millennials pose a challenge for marketers because they do not seek their entertainment and information from traditional media. Estimates of newspaper readership by this age group indicate low interest since the Millennials are one-third less likely to read newspapers than older cohorts. This represents only $7 \%$ of the total newspaper readership. In contrast, in light of their requirement for faster, more immediate sources, the Internet is certainly their medium of choice (Luo et al., 2005).

In the context of e-commerce advertising campaigns, Choi and Rifin say that the more consumers perceive that an online campaign is credible, believable, and/or trustworthy, the more likely they will engage in e-commerce, they have a higher probability of buying online (Choi and Rifon, 2002). According to Aiken and Boush (2006), an important criterion for perceived credibility of e-commerce websites is transaction-related privacy or security, and significant cues 
for trust are third-party certifications or "trustmarks". On the other hand, some researchers (Paek, Hole and Cole, 2013, Strážovská, Sulíková and Olvecká, 2016) also suggest that communication campaigners are likely to have limited results if they rely predominantly on social media, especially if they are focusing on a specific age group like Millennials.

\section{DATA AND METHODS}

The sample of this study consists of 190 Slovak Millennials who were chosen based on principles of convenience sampling. It is a non-probability sampling technique where subjects are selected because of their convenient accessibility and proximity to the researcher. It is a fast, inexpensive and easy technique. Respondents were presented a questionnaire with semantic differential scales, which is a "type of a rating scale designed to measure the connotative meaning of objects, events, and concepts or attitudes" (Darnell, 1970). To measure the perception of media credibility, 12 characteristics like objectiveness, activity, intelligence, professionalism, etc. were examined. The characteristics were in the form of adjectives and the respondents were asked to choose where their position lay, on a 7 point scale between two bipolar words. This method was used because semantic differentiation is a procedure that involves rather standard scaling practices and offers a variety of analytical methods.

The data was evaluated in SPSS, software for statistical computing and graphics. By assigning a set of integer values, such as $+3,+2,+1,0,-1,-2,-3$, to the seven gradations of each bipolar scale, the responses could be quantified under the assumption of equal-appearing intervals. These scale values were averaged across respondents in order to develop semantic differential profiles for all three examined media types. To test for the median differences, Wilcoxon signed-rank tests were used. The hypotheses for the test are: H0: if one observation is made at random from each population (call them $\mathrm{x} 0$ and $\mathrm{y} 0$ ), then the probability that $\mathrm{x} 0>\mathrm{y} 0$ is the same as the probability that $\mathrm{x} 0<\mathrm{y} 0$, and so the populations for each sample have the same medians. H1: the populations for each sample do not have the same medians. These hypotheses were tested on a 95 percent significance level.

\section{EMPIRICAL RESULTS}

The results of the study revealed moderate credibility of both newspapers and television. The highest overall credibility was perceived for the Internet. When examining statistically significant difference in overall perception, based on the results from the Wilcoxon signed-rank test we can conclude that the difference in perception of television and the Internet was unlikely to occur by chance $(p=0.03)$. The same result $(p=0.03)$ was measured in comparison of the Internet and newspapers. Testing the significant difference of means for television and newspapers showed no difference in credibility perception $(\mathrm{p}=0.21)$. Therefore we can conclude that the Millennials perceive the Internet as significantly more credible than television and newspapers.

The strengths of the Internet are telling the whole story, its activity and ability to act fast, objectivity, independence and interesting content. On the other hand, both television and newspapers are seen by the Millennials as better presented than the Internet. The worst rated feature for television and newspapers was their passivity and political background. 
Figure/Chart 1

Media credibility perception

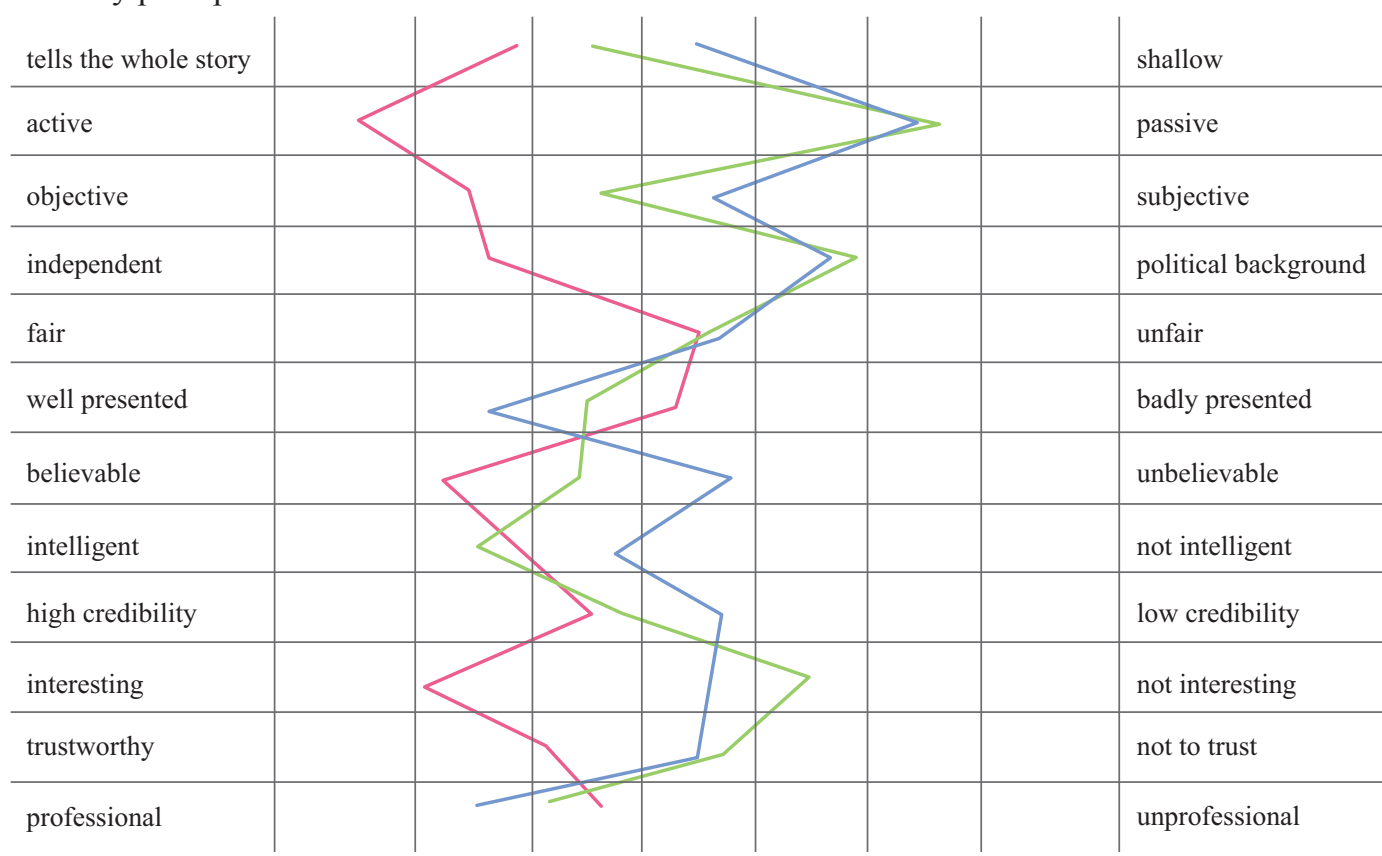

Source: Author's calculation

In general, the Internet is perceived as a relatively credible medium which is very active, objective and interesting. The Millennials find it believable, with moderate credibility and rather neutral level of fairness. Television is perceived by this cohort as very well presented with high level of professionalism and moderate objectivity, believability and credibility. On the other hand, it is also quite passive and with political background. The Millennials' attitudes towards newspapers can be described as neutral, with relatively high level of professionalism and intelligent content, rather passive and with political background.

When examining statistically significant difference in the independence of media, we can conclude that the difference in perception was unlikely to occur by chance $(p=0.02$ for Internet vs TV and $p=0.028$ for Internet vs newspapers) and therefore we can say that the Internet is perceived as independent in comparison to the TV and newspapers.

Since the p-values for activity are smaller than 0.05 , we conclude that the means are significantly different (we reject the null hypothesis H0) and the Internet is significantly more active than the traditional mass media.

Based on the results from the Wilcoxon signed-rank test, Millennials perceive the Internet as significantly more interesting than TV and newspapers $(\mathrm{p}=0.04$ for newspapers vs the Internet and $p=0.023$ for TV vs the Internet). In all other criteria, no statistically significant differences were found.

\section{DISCUSSION}

The Millennials are seen as a generation with significant purchasing power and influence, it is important to understand how they behave and what media they trust. By gaining a better understanding of how Millennials perceive credibility, companies can more appropriately plan and execute successful media campaigns directed to this very important public. 
Marketers might be worried that Millennials see the world in a different way since the news is just one of many sources and their discovery of events is rather incidental and passive. It is true that Millennials consume news and information in strikingly different ways than previous generations but their knowledge is anything but passive or uninterested. Their paths to discovery are more nuanced and varied than some may have imagined. Based on the research results we can say that new media are more credible than the traditional and the Millennials find the Internet significantly more active, with more interesting content and more independent than television and newspapers. The results also indicated that a significantly higher level of credibility was associated with new media than with traditional media. This concurs with previous findings by other researchers (Tsang et al., 2004; Luo et al., 2005; Calisir, 2003; Gangadharbatla, Bright and Logan, 2014).

These findings are valuable to communication specialists since this very important public is easy to address through the Internet. The advantage for organizations in using the Internet is that they can better target and improve their communication. Nevertheless, using this kind of media as a communication tool involves more than just delivering a message. It is important to listen and participate in conversations with the target audience.

Millennials consume more information than any other generation in history. The ability to process huge amounts of content is typical for this cohort. To make an impact, or even just get noticed, brands need to understand that Internet is the right channel. But the marketers cannot forget that the Millennials are very demanding and it must be taken into consideration that relevance and content is everything.

Generally speaking, the rules of communications have not changed, but the channels may vary according to the target audience. The Internet seems to be the most appropriate channel to address the Millenials. To succeed among Millennials means following the classical rules of communication while being mindful of the new media channels they trust the most.

\section{Implications and limitations of the study}

The findings of the current study provide both marketing researchers and practitioners with important implications. First, theoretically, the framework for investigating the matching effect of media credibility and Millennials established in this study provides a theoretical foundation for researchers who are interested in this topic. By using the same methodology performed in this study, researchers can accurately and appropriately examine behavior of Millenials and their attitudes toward media and their media consumption.

The presented study makes contributions to understanding how Millennials perceive credibility of various types of media. However, a number of important limitations need to be considered. First, the current research was not specifically designed to evaluate all the factors related to media credibility. Second, the research is not representative because of the sampling method and clearly the sample may not represent any definable population larger than itself. Non-probability sampling is a good method to use when conducting a pilot study; therefore, further research is required to obtain representative results. Thirdly, the generalizability of these results is subject to certain limitations. A number of possible future studies using the same experimental set-up would be a contribution to this topic.

\section{REFERENCES}

Aiken, K.D. and Boush, D.M. (2006) 'Trustmarks, objective- source ratings, and implied investments in advertising: Investigating online trust and the context-specific nature of Internet signals', Academy of Marketing Science, Vol. 34 No. 3, pp. 308-323. 
Ashill, N.J. and Yavas, U. (2005) 'Importance of information sources and media evaluations: a cross-national study', International Journal of Cross Cultural Management, Vol. 12, pp. 51-62.

Berndt, A. (2007) 'Media habits among Generation Y consumers', Proceedings of the 19th Annual Conference of the Southern African Institute of Management Scientists (pp. 3-16). Johannesburg, South Africa, 19-21 September 2007.

Calisir, F. (2003) 'Web advertising vs. other media: young consumers' view', Internet research: electronic networking applications and policy, No. 13, pp. 356-363.

Choi, S.M. and Rifon, J.N. (2002) 'Antecedents and consequences of web advertising credibility: A study of consumer response to banner ads', Journal of Interactive Advertising, Vol. 3 No. 1, pp. 10-14.

Davood M. et al. (2010) 'Research Attention to the Credibility of Information Sources', Media Ethics, Vol. 21 No. 2 , p. 35 .

Darnell, K. (1970) Semantic differentiation. Methods of Research in Communication. Boston: Houghton Mifflin Company, p. 188.

Eveland, W.P. and Shah, D.V. (2003) 'The impact of individual and interpersonal factors on perceived news media bias', Political Psychology, Vol. 24 No. 1, pp. 101-117.

Flanagin, A.J. and Metzger, M.J. (2008) 'Digital media and youth: Unparalleled opportunity and unprecedented responsibility', Digital media, youth, and credibility, pp. 5-27.

Gangadharbatla, H., Bright, L.F. and Logan, K. (2014) 'Social Media and news gathering: tapping into the millennial mindset', The Journal of Social Media in Society, Vol. 3 No. 1, pp. 45-63.

Gefen, D. (2000) 'E-Commerce: The role of familiarity and trust', Omega-International Journal of Management Science, Vol. 28, p. 729.

Golan, G.J. and Baker, S. (2012) 'Perceptions of Media Trust and Credibility Among Mormon College Students', Journal of Media and Religion, Vol. 11 No. 1, pp. 31-43.

Gunther, A. C. (1992) 'Biased press or biased public? Attitudes towards media coverage of social groups', PublicOpinion Quarterly, Vol. 56, No. 2, pp. 147-167.

Hilligoss, B. and Soo Yung, R. (2008) 'Developing a unifying framework of credibility assessment: Construct, heuristics, and interaction in context', Information Processing \& Management, Vol. 44 No. 4, p. 1475.

Luo, M., Feng, R. and Cai, L. (2005) 'Information search behavior and tourist characteristics: the Internet vis-à-vis other information sources', Journal of Travel and Tourism Marketing, Vol 17 No. 3, pp. 15-25.

McCorkindale, T., DiStaso, M.W. and Sisco, H.F. (2013) 'How millennials are engaging and building relationships with organizations on Facebook', The Journal of Social Media in Society, Vol. 2 No. 1, pp. 38-44.

O’Keefe, D.J. (1990) Persuasion: Theory and Research. Newbury Park, CA: Sage, p. 133.

Olšavský, F. (2013) Generation approach in operating of the target market-opportunities and risks. Theory and practice in management. Bratislava: Univerzita Komenského v Bratislave, pp. 122-131.

Paek, H.J., Hove, T., and Cole, R.T. (2013) 'A Multimethod Approach to Evaluating Social Media Campaign Effectiveness', System Sciences, 46th Hawaii International Conference on IEEE, pp. 1570-1579.

Savolaien, R. (2013) Media credibility and cognitive authority. The case of seeking orienting information [online] Retrieved 2015-03-12 from http://InformationR.net/ir/12-3/paper319.html.

Schewe, C.D. and Meredith, G. (2004), 'Segmenting global markets by generational cohorts: determining motivations by age', Journal of Consumer Behaviour, Vol. 4 No. 1, pp. 51-63.

Smolková, E. and Smolka, S. (2016) 'Koncipovanie marketingových stratégií modrých oceánov v spolupráci s partnerom', Marketing science and inspirations, Vol. 11 No. 1, pp. 22-34.

Sundar, S.S. (2008) The Main model: A heuristic approach to understanding technology effects on credibility. The John D. and Catherine T. MacArthur Foundation series on Digital Media and Learning, p. 89.

Stavrositu, C. and Sundar, S.S. (2008). 'If Internet credibility is so iffy, why the heavy use? The relationship between medium use and credibility', CyberPsychology \& Behavior, Vol. 11, pp. 65-68.

Sulikova, R., Strazovska, L. and Olvecka, V. (2016) Influence of the Globalization on Doing Business in Slovakia. In Cross-Cultural Business Conference 2016, p. 122.

Tsang, M.M., Ho, S. and Liang, T. (2004) 'Consumer attitudes toward mobile advertising: an empirical study', International Journal of Electric Commerce, Vol.8, pp. 65-78.

Wathen, C.N. and Burkell, J. (2002) 'Believe it or not: factors influencing credibility on the Web', Journal of the American Society for Information Science and Technology, Vol. 53 No. 2, p. 135. 